九州大学学術情報リポジトリ

Kyushu University Institutional Repository

\title{
Some Primary Characteristics of Water Quality in a Closed Water Body in Sasaguri, Fukuoka Prefecture, Japan
}

Lap, Bui Quoc

Graduate School of Bioresource and Bioenvironmental Sciences, Kyushu University

Mori, Ken

Faculty of Agriculture, Kyushu University

Hirai, Yasumaru

Faculty of Agriculture, Kyushu University

https://doi.org/10.5109/9248

出版情報：九州大学大学院農学研究院紀要. 51 (2)，pp.315-321，2006-10-27. Faculty of Agriculture, Kyushu University

バージョン：

権利関係 : 


\title{
Some Primary Characteristics of Water Quality in a Closed Water Body in Sasaguri, Fukuoka Prefecture, Japan
}

\author{
Bui Quoc LAP ${ }^{1}$, Ken MORI* and Yasumaru HIRAI
}

\author{
Laboratory of Bioproduction and Environment Information Sciences, Division of Bioproduction and \\ Environment Information Sciences, Department of Bioproduction and Environment Science, \\ Faculty of Agriculture, Kyushu University, Fukuoka 812-8581, Japan \\ (Received June 21, 2006 and accepted July 24, 2006)
}

\begin{abstract}
In closed water bodies such as lakes and reservoirs, due to the poor exchange rate with external water sources, many problems with their water quality easily occur such as thermal stratification, lack of dissolved oxygen in the bottom layers, and other water quality problems. Thermal stratification which is dependent greatly on meteorological conditions, is one of important features, which has great impact on water quality in the closed water bodies. To examine the variation of their water quality in response to the change in environmental factors such as meteorological conditions, Tabiishidani reservoir, which is located in Sasaguri town, Fukuoka prefecture, Japan was chosen as a case of study. Field observations on meteorological conditions ( solar radiation, relative humidity, wind speed, wind direction, air temperature ) were made by a system of meteorological sensors, while the measurement of the water quality was performed in site by using the multi-probe (W-23XD series, Horiba, Ltd., Kyoto-Japan). The results of this research have shown many valuable information on water quality in Tabiishidani reservoir under different meteorological patterns. Besides, the results would play an important part as inputs for simulating the wind-induced circulation and water quality in the reservoir, which would be studied in further researches.
\end{abstract}

\section{INTRODUCTION}

It is well known that lakes and reservoirs are major surface water sources for life. Human life depends on them for a multitude of uses including drinking, power generation, navigation, agricultural irrigation, etc., but they may be also subject to pollution caused by these and other activities, which may degrade their water quality (Lap and Mori, 2006). Furthermore, in closed water bodies such as lakes and reservoirs, due to the poor exchange with external water sources, thermal stratification, lack of oxygen in the bottom layer, eutrophication and other water quality problems easily occur. Thermal stratification in closed water bodies, which is dependent greatly on meteorological conditions, is one of important features, which has great impact on the ecological environment in reservoirs (Yun et al., 2001). Depending on the season, heat transfer tends to either raise or lower the temperature in the top layers of lakes or reservoirs as a consequence of factors, including solar radiation, air temperature, relative humidity, wind speed, causing the different distribution of water temperature along the depth of lakes or reservoirs, which is called the thermal stratification. Winds blowing over the lake's surface tend to mix the surface waters and transfer heat down through the water column (Chapra, 1997) by causing the wind-induced flow in the lake (Lap and Mori, 2006). However, due to the thermal stratification, in summer, waters in the top lay-

${ }^{1}$ Laboratory of Bioproduction and Environment Information Sciences, Division of Bioproduction and Environment Information Sciences, Department of Bioproduction and Bioenvironment Sciences, Graduate School of Bioresource and Bioenvironmental Sciences, Kyushu University

* Corresponding author (E-mail: moriken@bpes.kyushu-u.ac.jp) ers are usually lighter than those in the bottom layers, which can be resistant to the mixing in closed water bodies. This phenomenon can be a cause contributing to the lack of dissolved oxygen in the bottom of many closed water bodies.

In order to preserve and improve the water environment in such closed water bodies, it is essential to clarify the various biological and physical processes taking place in the closed water bodies in response to the variation of environmental factors such as meteorological conditions. From that perspective, Tabiishidani reservoir which is located in Sasaguri town, Fukuoka prefecture, Japan was chosen as a case of study to examine its variation in water quality over a daily cycle under different seasons. Through this research, valuabe information on water quality in a closed water body has been shown as below.

\section{MATERIALS AND METHODS}

\section{Study area}

Tabiishidani reservoir is a small reservoir which is located in Sasaguri town belonging to Fukuoka prefecture in the south-west of Japan, as shown in Fig. 1.

The reservoir has an average depth of $2.2 \mathrm{~m}$. The length is about $80 \mathrm{~m}$, and the width is about $70 \mathrm{~m}$. The total water surface area is about $5600 \mathrm{~m}^{2}$. In general, the volume of inflow and outflow is zero; that is, there are no changes in water level.

Field observations were conducted during a day-and-night cycle, including meteorological observation and measurement of water quality in site. In a cycle of a year, there are usually more problems with closed water bodies' water quality in summer and autumn, such as thermal stratification, the excessive growth of aquatic plants than in other seasons. Therefore, the observation 


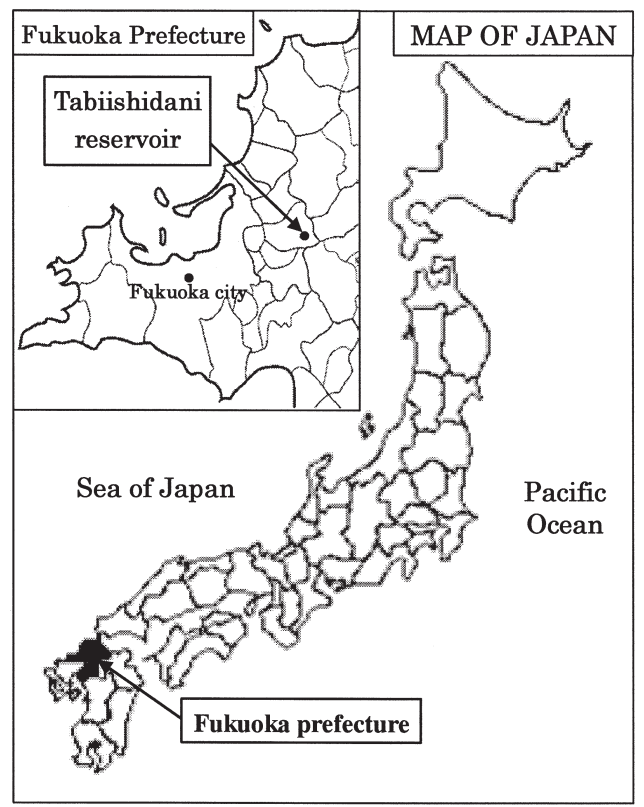

Fig. 1. Location of Tabiishidani reservoir in Fukuoka prefecture, Japan.

in this research was conducted in autumn, 2002 and in summer of 2003 as typical cases of study for Tabiishidani reservoir.

\section{Field observations}

\section{Meteorological observation}

Because meteorological conditions directly affect water quality in closed water bodies, it is necessary to conduct the meteorological observation in the study area. In this research, meteorological data measured directly in site include solar radiation, air temperature, relative humidity, wind speed and wind-direction.
These data were automatically recorded at every two minutes during a day-and-night cycle by a system of meteorological sensors, which is set up in site. They are used as one of the bases accounting for the variation of water quality parameters in closed water bodies.

Measurement of water quality parameters

The water quality parameters directly measured in site were water temperature $\left({ }^{\circ} \mathrm{C}\right)$, hydrogen ion concentration $(p H)$ and dissolved oxygen (DO) ( $\mathrm{mg} / \ell)$. These data were measured by using the multi-probe (W-23XD series, Horiba, Ltd., Kyoto-Japan). The water in the reservoir was divided into layers with $20 \mathrm{~cm}$ deep, and the measurement was done at the center of each layer.

\section{RESULTS AND DISCUSSION}

\section{Variation of meteorological factors in comparison with water temperature in the top layer of the reservoir.}

Figs. 2 \& 3 show the results of meteorological observation in comparison with variation of water temperature in the top layer of the reservoir on 09/25 \& 26, 2002 and 06/26 \& 27, 2003, respectively. From the Figs we can see that the change in water temperature in the top layer seems to be directly proportional to that of air temperature and solar radiation. During a day-time, when both solar radiation and air temperature were high, water temperature in the top layer was also high, while during a night-time, solar radiation was extinct, and air temperature fell, water temperature in the top layer also decreased. It also can be seen that the the amplitude of the change in water temperature in the top layer was relatively large. It means that water temperature in the top layer depends greatly on meteorological conditions.
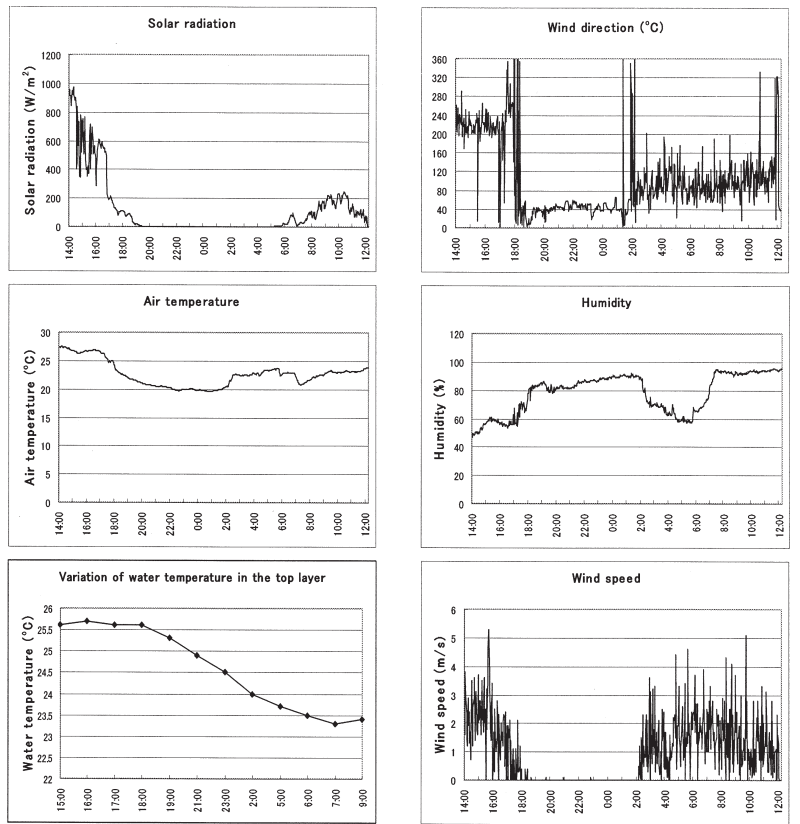

Fig. 3. The results of meteorological observation in comparison with water temperature in the top layer of the reservoir (measured 06/26 \& 27, 2003). 
Time-variation of water temperature, $\mathrm{DO}$ and $\mathrm{pH}$ within each water layer in the reservoir.

\section{Temperature change}

Temperature is a measure of how cool or how warm the water is, normally expressed in degrees Celsius $\left({ }^{\circ} \mathrm{C}\right)$. Temperature is a critical water quality parameter, since it directly influences the amount of dissolved oxygen that is available to aquatic organisms.

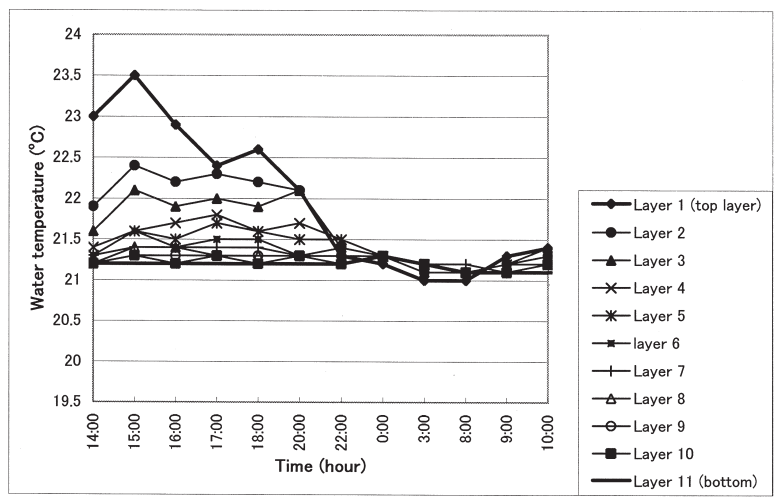

Fig. 4. Time-variation of water temperature within each water layer in the reservoir (09/25 \& 26, 2002).

Fig. 4 describes the time-variation of water temperature in each water layer in the reservoir. It can be seen that the change in water temperature in the top layer was the most significant and almost directly proportional to the change in air temperature and solar radiation (as shown in Fig. 2 above) while that in the bottom layer was nearly stable during a day-and-night period of the observation. It also shows that the deeper the water layer is, the less water temperature changes. That is because due to the surface layer is directly contiguous to the atmosphere, it is subject to meteorological conditions. Therefore, its water temperature changes according to the change of meteorological conditions. Water temperature in the surface layer, in turn, impacts that in the lower layers by convection and diffusion. This impact on the lower layers is inversely proportional to the depth between the surface layer and the lower layers. In other words, the lower the water layer is, the less it is affected by meteorological conditions. This phenomenon will be seen again in Fig. 5 below.

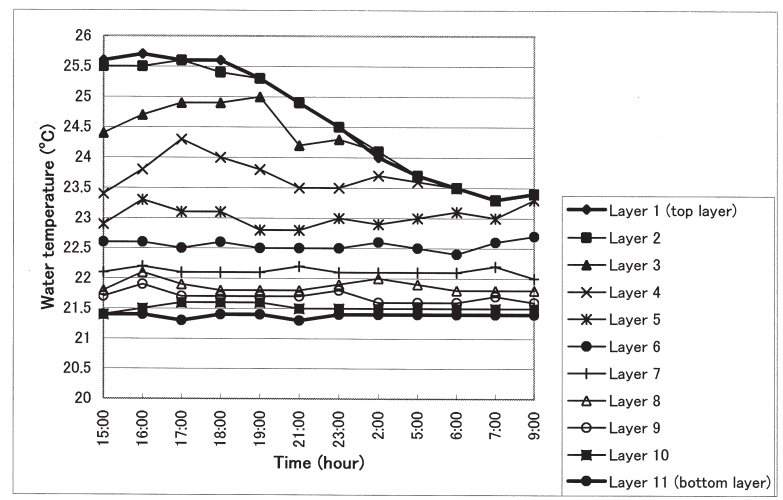

Fig. 5. Time-variation of water temperature within each water layer in the reservoir $(06 / 26 \& 27,2003)$.
Fig. 5 shows the time-variation of water temperature in each water layer in the reservoir on a day in summer. Similar to Fig. 4, the most significant change in water temperature took places in the top layer, the lower the water layer was, this change became less and less, and water temperature remained stable at about $21.4^{\circ} \mathrm{C}$ in the bottom layer during the period of the observation. Figs. $4 \& 5$ indicate that water temperature in the bottom layer was almost constant at about $21.2^{\circ} \mathrm{C}$ $-21.4^{\circ} \mathrm{C}$ during summer and autumn while the maximum water temperature $\left(25.7^{\circ} \mathrm{C}\right)$ taking place in the surface layer in summer was about $2.2^{\circ} \mathrm{C}$ higher than that in autumn $\left(23.5^{\circ} \mathrm{C}\right)$. The minimum water temperature in the top layer in summer was also higher than that in autumn (about $23.3^{\circ} \mathrm{C}$ in summer compared with $21.2^{\circ} \mathrm{C}$ in autumn). This is because air temperature in summer was higher than that in autumn (see Figs. 2 \& 3) leading to the higher temperature of the surface layer than that in autumn.

It can be seen from Fig. 4 that although the thermal stratification was very significant during the day-time, from 22:00 pm to 9:00 am of next day water temperature in all layers was nearly equal, in other words, the homogeneous state of water temperature in the reservoir took place during this period. However, the situation is different for the result shown in Fig. 5. According to this result of the observation in Fig. 5, there was no the homogeneous state taking place during the period of the observation.

The vertical distribution of water temperature in the reservoir would be clarified in Figs. $10 \& 11$ below.

\section{DO change}

$D O$ is short for dissolved oxygen. It expresses the amount of oxygen dissolved in water, normally measured in milligrams per liter $(m g / \ell)$. The oxygen content of natural waters varies with temperature, salinity, turbulence, the photosynthetic activity of algae and plants, and atmospheric pressure (UNESCO/WHO/UNEP, 1992). This component in water is critical to the survival of various aquatic lives such as fish.

Figs. 6 \& 7 show the time-variation of $D O$ in each water layer in the reservoir on 09/25\& 26, 2002 and on $06 / 26 \& 27,2003$, respectively. It can be seen from the Figs that in general, $D O$ in the upper layers was usually higher than that in the lower layers. The change in DO

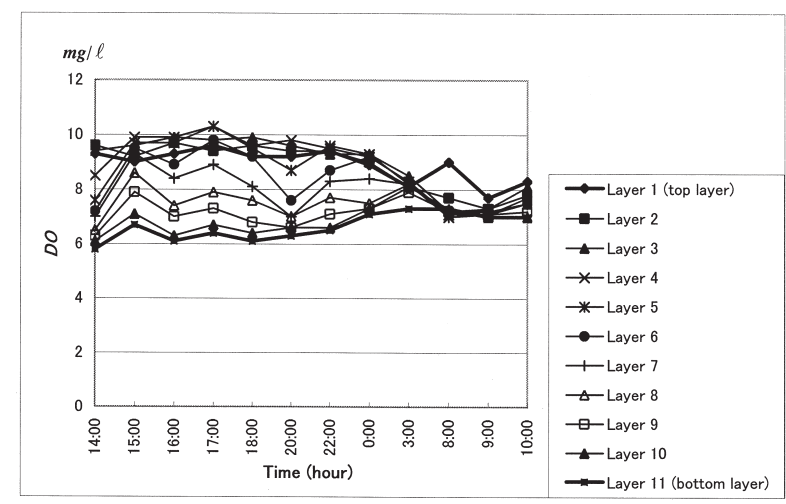

Fig. 6. Time-variation of $D O$ within each water layer in the reservoir (09/25 \& 26, 2002). 


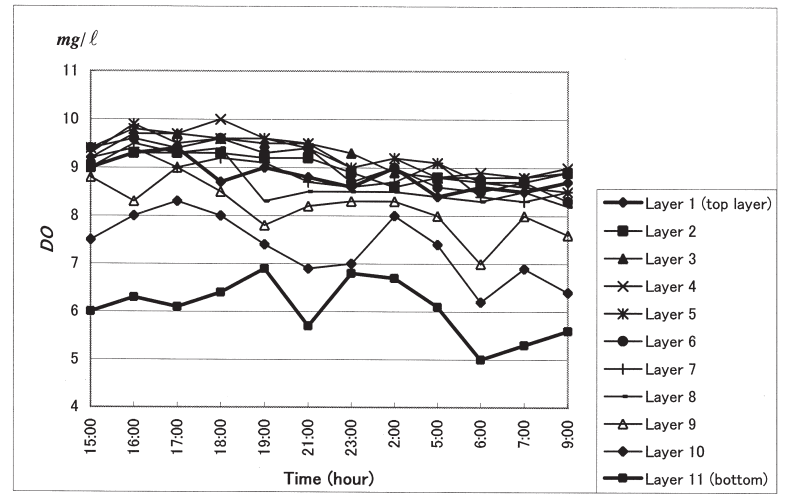

Fig. 7. Time-variation of $D O$ within each water layer in the reservoir (06/26 \& 27, 2003).

of the upper layers seems to be slightly proportional to the change in water temperature. The vertical stratification of $D O$ in summer is shown very clearly in Fig.7 while there was a nearly homogeneous state of $D O$ in the reservoir during 8:00 am-9:00 am on 09/26, 2002 (see Fig. 6). This phenomenon would be clarified in Fig. 12 below. In general, the values of $D O$ in both seasons were greater than $5 \mathrm{mg} / \ell$ that is the standard value for class B of natural lakes and reservoirs' water quality (MEJ, 1993)

\section{pH change}

$p H$ is a measure of the concentration of hydrogen ions in the water. This measurement indicates the acidity or alkalinity of the water. It is an important variable in water quality assessment as it influences many biological and chemical processes within a water body and all processes associated with water supply and treatment (UNESCO/WHO/UNEP, 1992). Water with $p H$ less than 5 or greater than 9 will support little aquatic life.

Figs. $8 \& 9$ indicate the time-variation of $p H$ in each water layer in the reservoir on 09/25 \& 26, 2002 and $06 / 26 \& 27,2003$, respectively. It can be seen that the stratification of $p H$ also took place during both the observation periods (09/25 \& 26, 2002 and 06/26 \& 27, 2003). The maximum values of $p H$ took place in the surface layer while the minimum values of it were in the bottom layer. The $p H$ values within each layer on $2002 / 09 / 25 \& 26$ seem to fluctuate more than those on $2003 / 06 / 26$ \& 27.

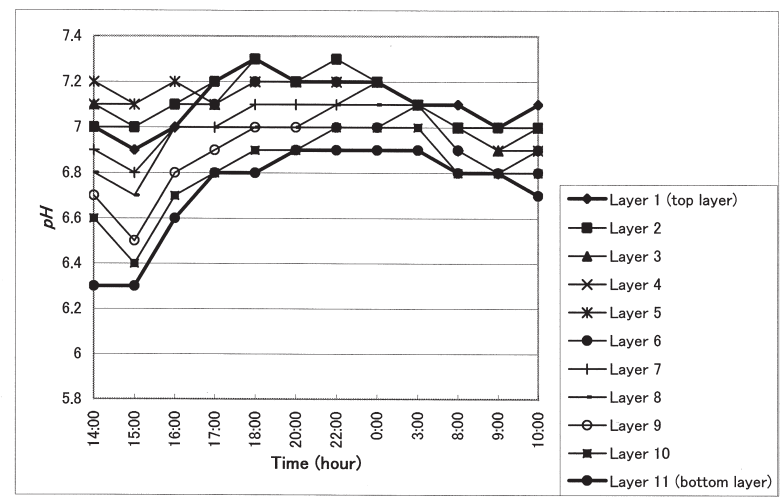

Fig. 8. Time-variation of $p H$ within each water layer in the reservoir $(09 / 25 \& 26,2002)$.

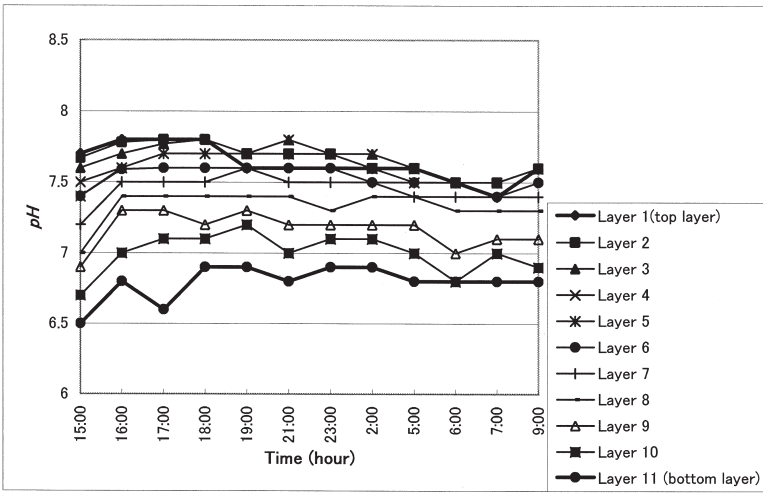

Fig. 9. Time-variation of $p H$ within each water layer in the reservoir (06/26 \& 27, 2003).

\section{Vertical distribution of water temperature, $D O$ and $\mathrm{pH}$.}

Vertical change in water temperature

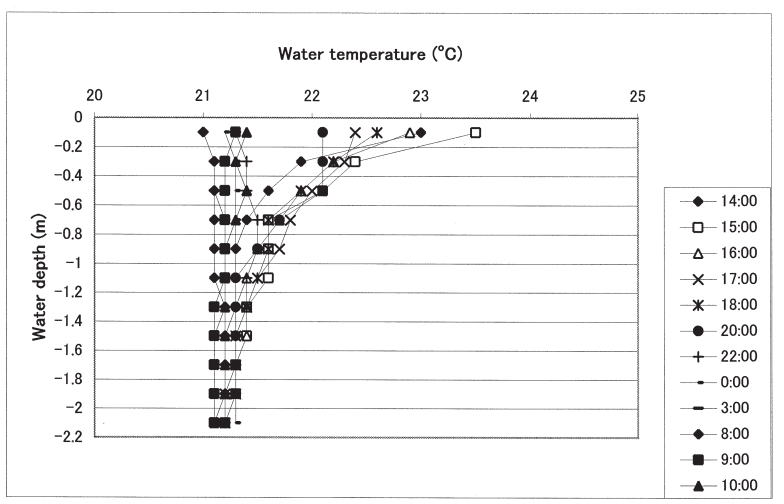

Fig. 10. Vertical distribution of water temperature (09/25 \& $26,2002)$.

Fig. 10 shows the vertical distribution of water temperature on $09 / 25 \& 26,2002$. It can be seen that from $14: 00 \mathrm{pm}$ to $18: 00 \mathrm{pm}$, the temperature difference between the upper layer and the bottom layer is significant; the thermal stratification reaches its maximum value at $15: 00 \mathrm{pm}$. The reason is that during this period (14:00 pm to $18: 00 \mathrm{pm})$, both solar radiation and air temperature are relatively high (see Fig. 2), causing to heat the water in the reservoir. Due to the fact that the upper layer absorbs most of the solar radiation, the water temperature in the upper layer is highest while that in the lower layers becomes lower with the depth because solar radiation is decreasingly absorbed with depth according to an exponential law. This period can be called the heating period of the reservoir.

Fig. 10 also indicates that at night from $22: 00 \mathrm{pm}$ to 10:00 am of the next day, water temperature in the upper layers decreased significantly, and the vertical distribution of water temperature in the reservoir was almost homogeneous at about $21.3^{\circ} \mathrm{C}$. It is because at night air temperature fell and solar radiation was also extinct (see Fig. 2), leading to the absence of energy for heating the water, and the heat release from the water to the atmosphere took place as air temperature fell 
lower than that in the water of the reservoir. As a result, the water temperature in the upper layer decreased and a homogeneous state of temperature took place from 22:00 pm to 10:00 am of the next day.

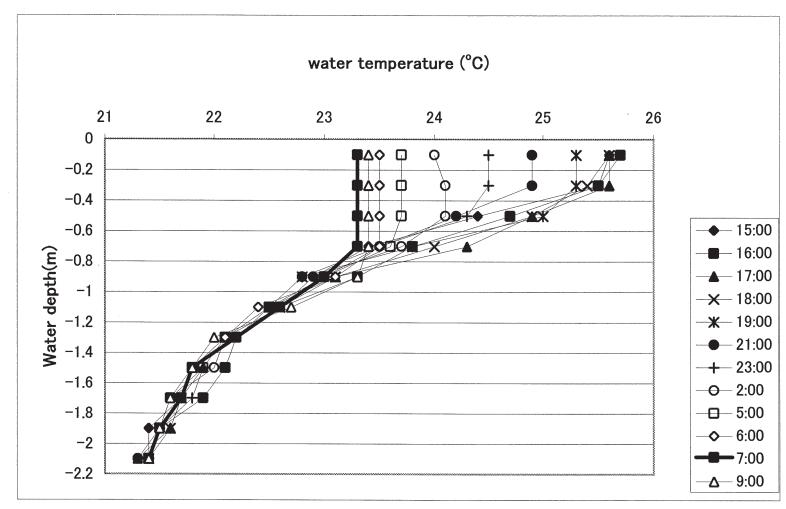

Fig. 11. Vertical distribution of water temperature $(06 / 26 \&$ 27, 2003).

Fig. 11 indicates the vertical distribution of water temperature during the period of the observation on 06/26 \& 27, 2003. From Fig. 11 we can see that unlike the situation shown in Fig. 10 where the nearly homogeneous temperature state occurred at night from 0:00 am to 9:00 am (see Fig. 10), the thermal stratification dominated completely during the period of the observation. The difference in water temperature between the top layer and the bottom layer is very significant. The thermal stratification reached its maximum value from $15: 00 \mathrm{pm}$ to $18: 00 \mathrm{pm}$. It is longer than the time of the maximum thermal stratification took place on 09/25 \& 26, 2002 (see Fig. 10). From 19:00 pm to 9:00 am of the next day, water temperature in the layers in the top one-third of the reservoir decreased gradually while water temperature in the layers in the bottom two-thirds of the reservoir nearly remained constant.

This distribution on water temperature can be explained that from 15:00 pm to 18:00 pm both solar radiation with high intensity and high air temperature were present (see Fig. 3). Therefore, during this period water temperature was heated and the maximum thermal stratification occurred and existed. At night, due to the absence of solar radiation and the decrease in air temperature, water radiated heat to the atmosphere, and water temperature in the upper layers decreased gradually. As can be seen in Fig. 11, the difference in water temperature between the top layer and the bottom layer was very significant, creating the difference in water density between them. As a result, the heavier waters in the lower layers were overlaid by lighter waters in the upper layers. This reason made the reservoir more difficult to circulate to mix waters in the upper layers into the lower layers. Consequently, the waters in the bottom two-thirds of the reservoir nearly remained constant while only the waters in the top one-third of the reservoir changed as shown in Fig. 11. The reason for the change in water temperature in the top one-third of the reservoir was attributed mainly to the phenomenon of heat conduction between water temperature in the reservoir and the atmosphere. This complete thermal stratification affected the distribution of $D O$ in the reservoir, which would be discussed below.

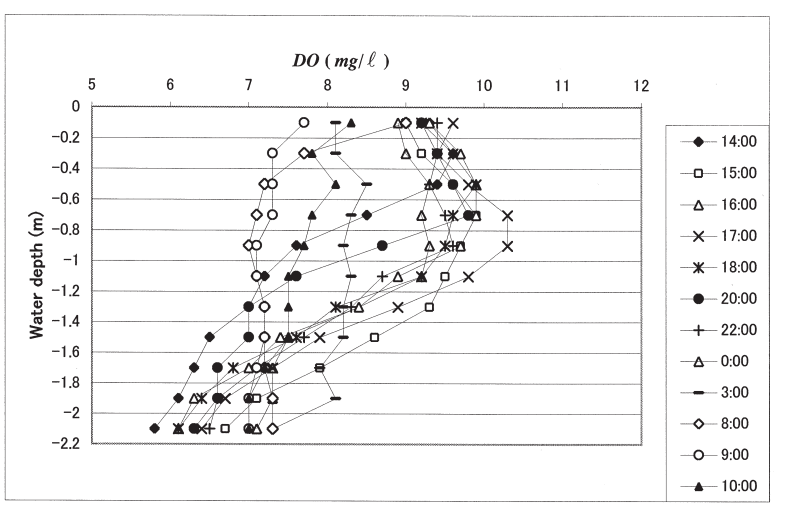

Fig. 12. Vertical distribution of $D O(09 / 25 \& 26,2002)$.

\section{Vertical change in DO}

Fig. 12 shows the vertical profile of $D O$ distribution on 09/2 5\& 26, 2002 (a day in autumn). It can be seen that in general, DO concentration in the upper layers was significantly higher than that in the lower layers, and the $D O$ in the bottom layer got its minimum value. This is because the upper layers receive more oxygen from the atmosphere by reaeration and more sunlight which is a factor stimulating photosynthesis process in the upper layers to create an additional amount of $D O$ as shown in the reaction below :

$$
6 \mathrm{CO}_{2}+6 \mathrm{H}_{2} \mathrm{O} \underset{\text { Respiration }}{\stackrel{\text { Photosynthesis }}{\longrightarrow}} 6 \mathrm{O}_{2}+\mathrm{C}_{6} \mathrm{H}_{12} \mathrm{O}_{6}
$$

However, the lower layers are physically separated from the atmosphere (which is a source of gases such as oxygen) by the upper layers and may be in contact with decomposing sediments in the bottom, which need an oxygen demand. As a result of these influences, it is common for the lower layer to have a significantly decreased oxygen concentration compared with the upper layer. The difference in $D O$ between the upper layer and bottom layer is supported partly by thermal stratification. Due to thermal stratification, water density gradients take place vertically, causing the mixing in closed water bodies to become more difficult. As a result, the vertical difference in $D O$ is maintained.

It is interesting that from 3:00 am to 10:00 am, DO distribution seems to be almost homogeneous vertically. This phenomenon can be explained that during this period (3:00 am to 10:00 am), the vertical distribution of water temperature in the reservoir became nearly homogeneous (see Fig. 10), making the mixing in the reservoir more active. As a result, the vertical difference in DO was narrowed.

Fig. 13 shows the profile of $D O$ distribution during the period of the observation on $06 / 26 \& 27,2003$. It is easy to see that unlike the situation described in Fig. 12 where $D O$ on that day $(09 / 25 \& 26,2002)$ was in the nearly homogeneous state when the water temperature 


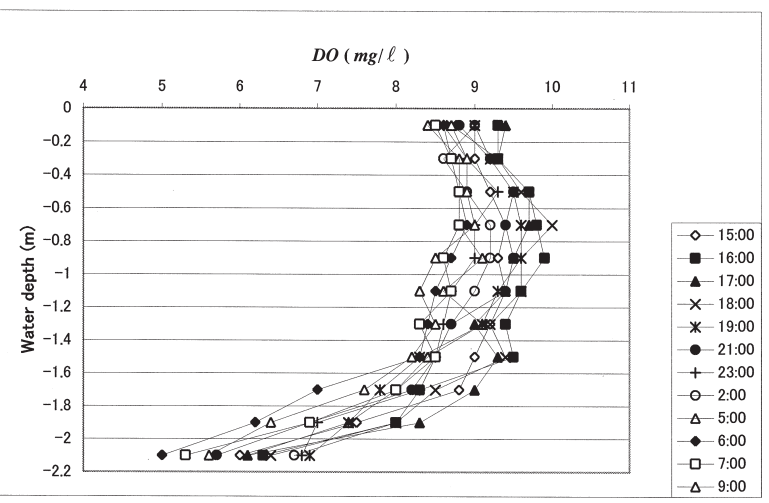

Fig. 13. Vertical distribution of $D O(06 / 26 \& 27,2003)$.

became homogeneous, $D O$ on $06 / 26 \& 27,2003$ was stratified significantly. The reason could be that due to the significant thermal stratification (See Fig. 11), the wind was not effective enough to make the reservoir circulate by mixing waters in the upper layers into the lower layers. As a result, the difference in DO between the upper layers and the lower layers was maintained.

Vertical change in $\mathrm{pH}$

Figs. $14 \& 15$ show the vertical distribution of $p H$ on $2002 / 09 / 25 \& 26$ and on 2003/06/26 \& 27, respectively. In general, the difference in $p H$ between the upper layers and the lower layers was not large. However, it can be seen that the $p H$-values in the bottom layer always get their minimum value during the periods of

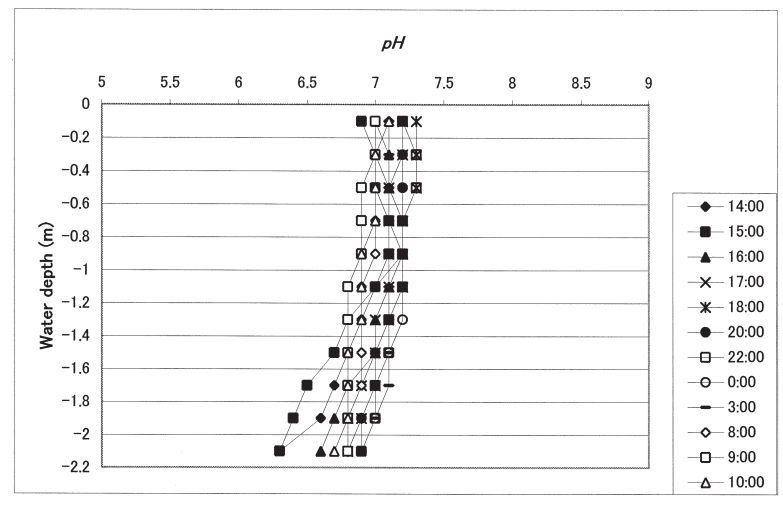

Fig. 14. Vertical distribution of $p H(09 / 25 \& 26,2002)$.

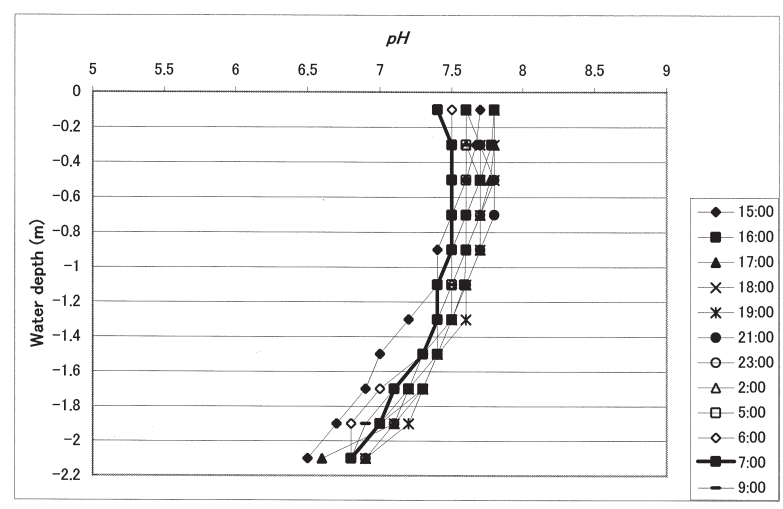

Fig. 15. Vertical distribution of $p H(06 / 26 \& 27,2003)$. the observation including both on 09/25 \& 26, 2002 and on 06/26 \& 27, 2003 (see Figs. 8, 9, 14 and 15). The reason could be that waters in the bottom layer is in contact with decomposing sediments in the bottom of the reservoir, which need an oxygen demand to decompose the organic matters in the bottom in the reverse respiration reactions as shown in the reaction (1) above. As the respiration takes place, it consumes oxygen, and $\mathrm{CO}_{2}$ is liberated. $\mathrm{CO}_{2}$, in turn, combines with water to form carbonic acid as follows:

$$
\mathrm{CO}_{2}+\mathrm{H}_{2} \mathrm{O} \longrightarrow \mathrm{H}_{2} \mathrm{CO}_{3}
$$

The carbonic acid, in turn, dissociates into ionic form as below.

$$
\begin{aligned}
& \mathrm{H}_{2} \mathrm{CO}_{3} \longrightarrow \mathrm{HCO}_{3}^{-}+\mathrm{H}^{+} \\
& \mathrm{HCO}_{3}^{-} \longrightarrow \mathrm{CO}_{3}^{2-}+\mathrm{H}^{+}
\end{aligned}
$$

As a result of the process from (2) to (4), the amount of hydrogen ion increases, making the waters in the bottom layer become more acid or the decrease in $p H$. This reason is also confirmed by referring to the profiles of DO distribution in Figs. 12 \& 13 where DO in the bottom layer always got its minimum value, which was attributed to the fact that more $D O$ in the bottom layer was consumed in the reverse respiration reaction (1).

\section{CONCLUSIONS}

From the data gathered and analyzed above, some primary characteristics of water quality in a closed water body would be summarized as follows:

1. Water temperature in closed water bodies is closely related to the meteorological conditions. In a diurnal cycle, in autumn, thermal stratification develops in the afternoon and destroyed gradually during the night to become homogeneous in the early morning. However, due to the higher temperature in summer than that in autumn, thermal stratification seems to be remained during the diurnal cycle.

2. In closed water bodies, DO in the bottom layer usually has its minimum value due to the fact that it is in contact with decomposing sediments in the bottom, which need an oxygen demand to decompose organic matters in the bottom. DO is also stratified as water temperature is stratified, and it become more homogeneous as water temperature is homogeneous.

3. $p H$ in closed water bodies is also stratified and its minimum value is usually present in the bottom layer of the closed water bodies because the respiration and decomposition processes of the organic matters in the bottom layer create $\mathrm{CO}_{2}$ which is further combined with water to form $\mathrm{H}_{2} \mathrm{CO}_{3}$ in the bottom layer. As a result, $p H$ in the bottom water layer of the closed water bodies is usually smaller than that in the upper layers. 
In short, in closed water bodies, the vertical distribution of water temperature is dependent on the meteorological conditions. Water temperature, in turn, directly affects the mixing of the closed water bodies. The mixing, in turn, influences the distribution of other water quality variables in closed water bodies.

\section{REFERENCES}

Chapra, S. C 1997 Surface water-quality modeling. McGraw-Hill, New York

Horiba, Ltd. 2001 Multi-Probe W-20XD Series W-22XD. 23XD. Operation Manual. Kyoto-Japan

Lap, B. Q. and K. Mori 2006 A two-dimensional model for water quality simulation in lakes and its application to Tabiishidani reservoir in Sasaguri-Fukuoka prefecture, Japan. J. Fac. Agr., Kyushu Univ., 51(1): 19-27

Lap, B. Q. and K. Mori 2006 A two-dimensional simulation of flow field in lakes under wind acting on the water surface and the impact of aquatic plants on the flow patterns. J. Fac. Agr., Kyushu Univ., 51(1): 13-18

Ministry of the Environment of Japan (MEJ) 1993 Environmental quality standards for water pollution. in http://www.env.go.jp/en/lar/regulation/wp.html

UNESCO/WHO/UNEP 1992 Water Quality Assessment -A Guide to Use of Biota, Sediments and Water in Environmental Monitoring-Second Edition. In http://www.who.int/docstore/ water_sanitation_health/wqassess/begin.htm\#Contents

Yun, D., Z. Wenqian, L. Jia and L. Lin 2001 Simulation on thermal stratification of the huge-cubage and deep reservoirs. In http://www.iahr.org/e-library/beijing_proceedings/HTML/hom epage.html 